\title{
Artifıcial Intelligence in Enterprise Resource Planning Systems: A Bibliometric Study
}

Author(s): Cemal Aktürk

Source: Journal of International Logistics and Trade 2021; 19(2):69-82

Published by: Jungseok Research Institute of International Logistics and Trade, Inha University

DOI: https://doi.org/10.24006/jilt.2021.19.2.069

Journal of International Logistics and Trade is an official journal published by Jungseok Research Institute of International Logistics and Trade, Inha University, Korea. JILT welcomes manuscripts that advance the practice and science of logistics, trade, and other related fields.

Frequency: Quarterly (March, June, September, December)

Stable URL: https://www.ejilt.org

Jungseok Research Institute of International Logistics and Trade is a specialized academic research institute representing Inha University and Inha Foundation in Korea. The institute aims to become a representative institute in Northeast Asia in the research of logistics and trade.

Stable URL: https://jrieng.inha.ac.kr

(C) Copyright. Jungseok Research Institute of International Logistics and Trade.

This is an Open-Access article distributed under the terms of the Creative Commons Attribution NonCommercial License (http://creativecommons.org/licenses/by-nc/4.0/) which permits unrestricted noncommercial use, distribution, and reproduction in any medium, provided the original work is properly cited 



\section{Journal of International Logistics and Trade}

J. Int. Logist. Trade, 2021, Vol. 19, No. 2, 69-82

pISSN : 1738-2122 eISSN : 2508-7592

https://doi.org/10.24006/jilt.2021.19.2.069

ARTICLE

\section{Artificial Intelligence in Enterprise Resource Planning Systems: A Bibliometric Study}

\section{Cemal Aktürk*}

Gaziantep Islam Science and Technology University, Gaziantep, Turkey

Received April 11, 2021
Revised May 15, 2021
Accepted June 18, 2021

*Corresponding author: Cemal Aktürk
Gaziantep Islam Science and Technology
University, Gaziantep, Turkey
Tel: +905427192916
E-mail: cemal.akturk@gibtu.edu.tr

\section{Introduction}

Enterprise Resource Planning (ERP) systems are information systems in which all business processes in the supply chain such as purchasing, ordering, manufacturing, quality control, shipment, finance, and accounting are managed in an enterprise that produces goods or services. In other words, ERP is a business management software that integrates business processes with an organization's data sources (Bahssas et al. 2015). Instant recording of movements in an organization's material, energy, labor, and financial resources ensures the production of data and information for different management levels with ERP systems. An ERP system generally consists of modules such as supply chain, customer relationship management, accounting, finance, manufacturing, and human resources. Each module actually enables the actual business processes in the enterprise to be operated in parallel on digital platforms.

Inventory management software forms the basis of ERP systems with the introduction of computer use that emerged in the 1960s. Material requirements planning (MRP) systems were developed in 1970 and manufacturing requirements planning (MRP-II) systems were developed in late 1980 especially for use in manufacturing. ERP systems have been developed that integrate MRP and MRP-II used in manufacturing with other business processes such as accounting, finance, human resources, customer relationship management since 1990 (Al-Mashari et al. 2003; Bahssas et al. 2015; Gibson et al. 1999).

ERP systems ensure the integration of business processes, data integrity, data security, and business efficiency whereas at the same time enabling managers to make effective and fast decisions about ongoing business operations. In addition, the use of ERP positively affects the profitability and thus the competitiveness of the business as it enables the effective management of resources such as materials, labor, energy, and money and the reduction of costs. Azevedo et al. (2014) present factors that may hinder the competitiveness of organizations in the use of the ERP system in the hospitality industry by supporting a group of Portuguese companies with a case study. The researchers emphasized that the quality of service is negatively affected due to
Keywords Enterprise resource planning, Artificial intelligence, Bibliometric analysis, Business process management

\begin{abstract}
Improving business processes provides companies with advantages in terms of
efficiency and profitability, as well as competitiveness against other companies in the market. Companies that integrate business processes with enterprise resource planning
(ERP) systems into digital platforms also have the opportunity to strengthen their weaknesses by recognizing disruptions and bottlenecks in inefficient business processes in this study for a systematic evaluation of studies on artificial intelligence (AI) in the ERP
literature. The studies in which the keywords determined from the AI literature were firstly used together with ERP were investigated from the Scopus database. 837 publications meeting the search criteria were reached and a descriptive analysis of these publications was citation, and common keyword analysis methods for 296 publications in the article type. results. The most commonly used AI keywords in the ERP studies were "genetic algorithm", "fuzzy logic", and "machine learning". This study aims to guide future studies by providing a systematic and new perspective to researchers and experts working on ERP-AI. thanks to this digital transformation. Descriptive and bibliometric analyses were performed
\end{abstract}


the fact that the services provided to the customers in these business areas are not automatically reflected in the customer invoices in cases where the software in the business areas of hotels such as sports and healthcare centers are not integrated with the hotel's ERP system.

Mladenova (2020) examined 16 open source ERP systems for SMEs in terms of programming language, database management system, and the functions offered. The researcher showed that JAVA was the most preferred programming language and PostgreSQL was the most preferred database in the ERP systems she examined. Janssens et al. (2018) conducted a study that included the classification and comparison of 205 ERP project implementation studies obtained from the literature by 11 ERP application experts. The researchers emphasized that publications on this subject decreased even though ERP is a multidisciplinary field in their study. Cadersaib et al. (2020) aimed to analyze the skills needed in ERP implementation projects by examining the studies on ERP application skills through a systematic review. The researchers classified the skills in this regard as ERP skills, job, and problem-solving skills, interpersonal skills, knowledge management skills, strategy, and management skills according to the results of the analysis. ERP is a multidisciplinary field that includes information systems, accounting, management and organization, business management, and computer sciences as a research area (Schlichter and Kraemmergaard 2010).

Artificial Intelligence (AI) can be defined as the performance of human behaviors and tasks requiring skills such as understanding, generalizing, producing solutions, learning, and inferring from past experiences by computers or computeraided machines (Nabiyev 2012; Öztürk and Şahin 2018). Opinions about AI are generally discussed in four groups. These are thinking like a human, acting like a human, thinking rationally, and acting rationally (Pirim 2006). AI generally consists of methods that try to model the human brain's working system, human ability to think, and evolutionary development in nature. These methods can be listed as Simulated Annealing, Expert Systems, Computer Vision, Speech Recognition, Artificial Neural Networks, Fuzzy Logic, Support Vector Machine, Genetic Algorithms, Chaotic Modeling and Robotic (Tektaş et al. 2002). AI is used in the analysis of real-time data for purposes such as forecasting, planning, and optimization in order to make quick and effective decisions in the management of business processes. The use of AI only in a specific unit along a supply chain will be incomplete in achieving the necessary gains in terms of efficiency and profitability. The use of AI techniques in every possible business process in ERP systems, which provides the opportunity to handle business processes with a holistic approach, will significantly reduce costs while also positively affecting the efficient use of resources and increasing the profitability and competitiveness of the business for these reasons.

\subsection{Literature review}

Systematic analysis studies on ERP or business process management and AI studies are examined in the literature and the studies related to the subject of the research are presented under this heading.

The use of AI in demand forecasting, supply chain planning, and optimization problems is becoming increasingly widespread. Early preparation of products with AI, prevention of faulty product shipment, and reduction of delivery time contribute to efficiency in supply chain management. AI applications in supply chain management aim to solve problems such as selecting suppliers, estimating sales and purchasing demands, and determining transportation network (Çiftçi 2005; Pulat and Kocakoc 2019; Türk and Kiani 2019). Korkmaz (2020) classified the customer data for the financial sector according to the risk status by using artificial neural networks and support vector machine methods considering the studies using AI in the management of other business processes. Ünver and Altunok (2020) emphasized that using robots in the assembly line for the medical industry increases manufacturing efficiency by reducing human errors. In addition, it is stated that works that take a lot of time such as conducting recruitment processes in human resources management, conducting written and oral exams, matching candidates to vacant positions can be done with AI applications with high efficiency (Gür et al. 2019).

Schlichter and Kraemmergaard (2010) conducted a comprehensive literature analysis on ERP and presented a content analysis by journal, publication year, and author from the summaries of 885 publications published between 2000 and 2009. In addition, "implementation, post-implementation, organizational change, and managerial implications, ERP market and industry, ERP training, supply chain management and ERP" areas of interest were identified for the ERP research area. The study of researchers can form the basis for a systematic review of ERP. Cong and Shi (2019) conducted a content analysis and common word analysis to show the development of international cooperation networks and studies in studies conducted in different countries on clean manufacturing. Prashar (2020) examined 189 studies scanned in the Web of Science (WoS) database by performing content analysis and bibliometric analysis on sustainable development in small and medium-sized enterprises.

Ardito et al. (2019) presented a bibliometric analysis study for 478 articles reviewed in WoS on big data analytics in terms 
of business and management. Mourao and Martinho (2020) examined 83 articles published in the WoS database on forest entrepreneurship from a bibliometric point of view and presented the journal, country, author, and keyword networks of the articles with the VOSviewer software. Inacio and Marques (2018) conducted a bibliometric analysis of internal control in ERP systems and analyzed 57 publications they reached by examining the published studies on internal control and ERP in the Scopus database between 2003 and 2017. The researchers shared the results of descriptive analysis covering the results obtained from the Scopus platform in their study. Ivanov et al. (2020) reached 191 articles in an inquiry from journals scanned in the Scopus database to examine the latest developments in Industry 4.0 in terms of industrial engineering, operational management, management research, control, and data science. The researchers analyzed 191 articles in the VOSviewer software and reached 80 common keywords used at least 4 times. Lizano-Mora et al. (2021) performed a bibliometric analysis of studies on business process management in journals scanned in commonly used databases such as WoS, Scopus, IEEE Xplore, Google Scholar through R software.

Mladenova (2020) recommends that ERP systems should be developed in terms of "social network integration", "automation of processes", "use of autonomous devices", "utilizing the capabilities of IoT devices", "implementing voice control commands", "using big data analysis and machine learning". A broad perspective of ERP-AI studies is presented and it directs researchers to use AI techniques more in ERP systems as suggested by Mladenova (2020) in the study. In parallel, Janssens et al. (2020) stated that the number of studies on ERP increased day by day and emphasized that the multidisciplinary interest in ERP systems would continue to increase especially when considered together with AI and Industry 4.0.

Prashar (2020) conducted only common keyword analysis within the scope of the bibliometric method with numerical data of 189 studies obtained from the WoS platform. Ardito et al. (2019) performed document common citation analysis from bibliometric methods for articles reviewed in Wos on big data analytics in terms of business and management. Inacio and Marques (2018) shared the results obtained from the Scopus platform of 57 publications related to internal control and ERP, and did not perform bibliometric analyzes such as common author, common citation, or common keyword analysis, but only shared the results of descriptive analysis. Ivanov et al. (2020) subjected only 191 articles to common keyword analysis in the VOSviewer software. It is much more comprehensive in terms of quality and quantity in terms of the article examined and bibliometric analyses performed by using many AI keywords determined especially with ERP in this study.

\subsection{Research questions}

Descriptive analysis of all studies on ERP and AI techniques in the Scopus database and bibliometric analyses of those in the article type from these studies are presented in this study. This study aims to provide researchers, managers, and field experts working on ERP with a new roadmap to address the issue from a broader and systematic perspective, especially in terms of AI, which has wider use in managing business processes together with Industry 4.0. Answers to the following research questions were sought in the study.

What is the type and writing language of ERP-AI-related publications?

What is the distribution of ERP-AI publications by years?

Who are the authors which produced the most publications about ERP-AI?

What are the most ERP-AI-related institutions?

What is the distribution of ERP-AI publications by subject areas?

Who are the authors who received the most references about ERP-AI?

What is the collaboration of ERP-AI-related publications between co-authors?

What is the collaboration network of ERP-AI publications between co-authors' countries?

What are ERP-AI-related publications' common citation and collaboration networks between authors?

What is the collaboration network of ERP-AI publications between common references and sources?

What are the common keywords used in ERP-AI-related publications?

\section{Method}

\subsection{Data collection}

International publications obtained according to the search criteria related to ERP-AI topics in the Scopus database were examined by descriptive and bibliometric analysis methods in this study. Various keywords that are used together with the expression "enterprise resource planning" and that express AI techniques are used in the search query. These keywords have 
been compiled from techniques and terms used in AI-related studies in the literature. Keywords used in AI-related search queries are listed as follows.

"artificial intelligence", "machine intelligence", "neutral network*", "machine learn*", "deep learn*", "natural language process*", "thinking computer system", "expert system", "evolutionary computation", "hybrid intelligent system*", "fuzzy logic", "computer vision", "neural network*", "simulated anneal*", "support vector machine*", "genetic algorithm*", "agentbased systems", "intelligent agents", "intelligent tutoring", "autonomous robots".

These keywords were used by adding the "OR" operator to the search query. All of the keywords related to AI are enclosed in brackets and connected to the expression "enterprise resource planning" together with the operator "AND" to ensure coexistence. Thus, it is aimed to reach the studies using AI techniques in the studies conducted with ERP. A total of 837 studies meeting the criteria were reached with this search query. No filter was applied according to the publication year or any criteria since descriptive analyses will be performed primarily in the search results.

\subsection{Data analysis}

The data were analyzed in two different ways. The distribution of publications by years, types, and publication language, institutions, and sources was firstly obtained from the Scopus web page within the scope of descriptive analysis. In addition, the subject areas of the publications made with the authors and institutions who made the most publications within the scope of descriptive analysis were determined. Then, only those in the article type were filtered from 837 studies, and the data file in ".csv" format recorded for these articles was transferred to the VOSviewer software and bibliometric analyses were performed. Common author-writer analysis, common author-country analysis, common citation-writer analysis, common citation-journal analysis, and common keyword analysis were performed in this context. The data were analyzed with the help of the VOSviewer software and the keywords, authors, and country names formed with different characters were arranged before the analyses. VOSviewer is a software tool that supports recording formats from which search results can be exported from academic databases to create and visualize bibliometric networks. Through VOSviewer, researchers can have the opportunity to directly analyze the data of the search results they reach, without the need for pre-processing and coding. It can also quickly generate visual network maps. Due to these advantages in bibliometric studies, VOSviewer program was used.

\section{Results}

The results of the descriptive analyses conducted as a result of the studies conducted from the Scopus database are shared through tables and graphs.

\subsection{Distribution of publications according to their types and languages}

Table 1 shows the distribution of ERP-AI studies by type and writing languages. Table 1 shows that a total of 837 studies were conducted on ERP-AI subjects. Most publications $(n=479)$ appear to be in the type of conference paper. The second place is the articles $(n=296)$, which make up about a third of the publications. The vast majority $(94.27 \%)$ of the studies were written in English. However, there are 44 studies published in Chinese, 2 in Turkish, and 1 in Arabic and 1 in French.

\subsection{Distribution of publications by years}

The distribution of the studies by years is provided in Figure 1. It is seen in Figure 1 that studies on this subject have been carried out from 1995 to the present day. Most publications were made in $2018(\mathrm{n}=65)$. It is understood that there has been a significant increase in the number of studies conducted especially after 2000. It can be seen in Figure 1 that the interest in ERPAI studies increased from 2014 to 2019 while there is a tendency to decrease the number of publications between 2009 and 2014. The number of studies in 2021 was low since the data were collected as of March 2021 and 2021 was not yet over when this study was conducted. 
Table 1. Distribution of publications according to their types and languages

\begin{tabular}{|c|c|c|}
\hline Variable & Document & $\%$ \\
\hline Document type & 837 & 100 \\
\hline Conference paper & 479 & 57.23 \\
\hline Article & 296 & 35.36 \\
\hline Conference review & 22 & 2.63 \\
\hline Review & 22 & 2.63 \\
\hline Book chapter & 13 & 1.55 \\
\hline Editorial & 2 & 0.24 \\
\hline Note & 1 & 0.12 \\
\hline Short survey & 1 & 0.12 \\
\hline Retracted & 1 & 0.12 \\
\hline \multicolumn{3}{|l|}{ Language } \\
\hline English & 789 & 94.27 \\
\hline Chinese & 44 & 5.26 \\
\hline Turkish & 2 & 0.24 \\
\hline Arabic & 1 & 0.12 \\
\hline French & 1 & 0.12 \\
\hline
\end{tabular}

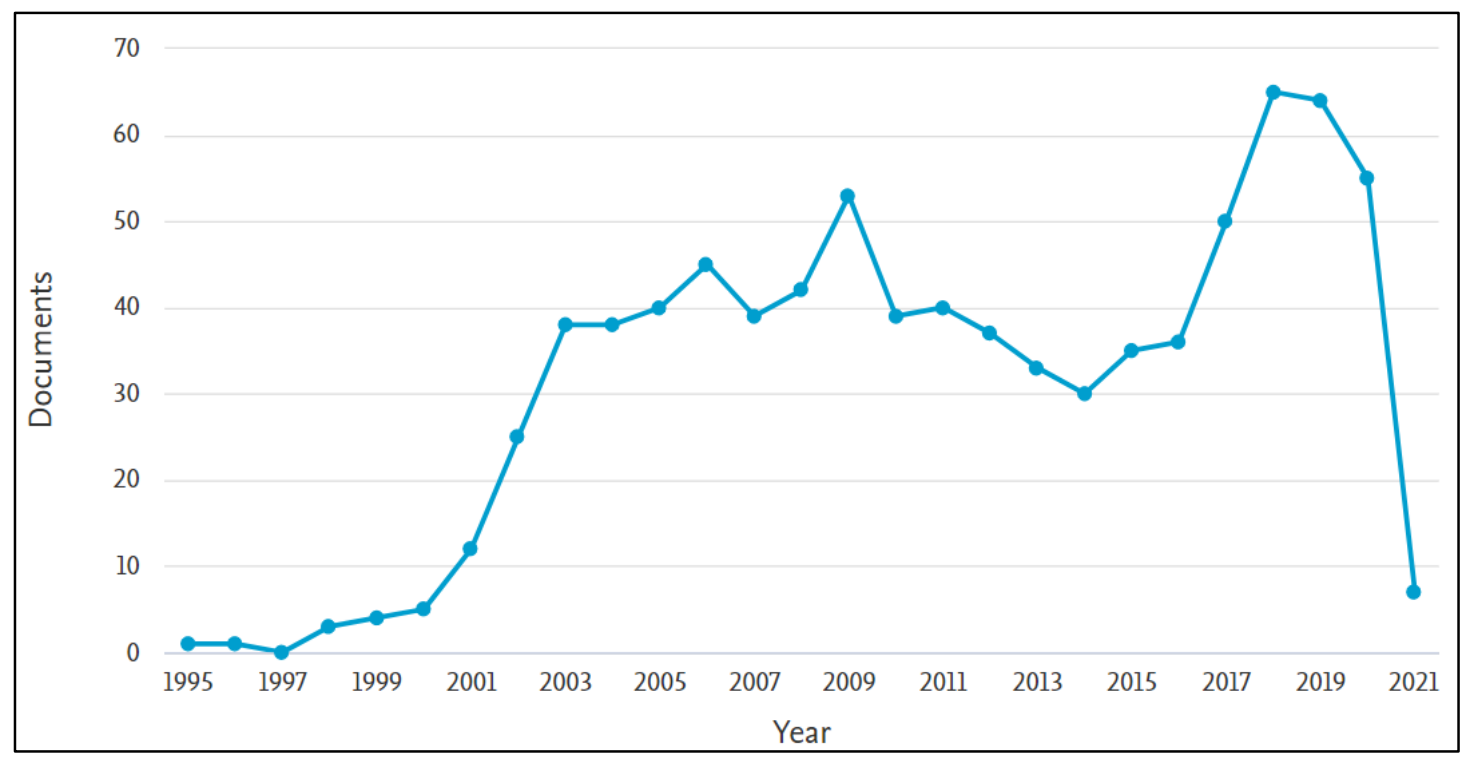

Figure 1. Distribution of publications by years.

\subsection{Authors and institutions}

Figure 2 shows the authors who published the most on ERP-AI topics. Most publications were made by Orosz, T accordingly $(\mathrm{n}=8)$. This researcher is followed by five publications by Koumpis, A and Wang, D. W. Chen, Y. L, Orosz, I., Ravasan, A. Z., Relich, M., Selmeci, A., Subramonaim, S. share fourth place in the ranking with four publications.

The data collection tool used in the research and the number of objective publications on the basis of institutions within the framework of the research boundaries are shown in Table 2. Table 2 shows the 15 institutions that published the most in the distribution of publications by institutions. Tsinghua University $(n=12)$ ranks first in the number of publications. Obuda University ranks second with 11 publications whereas Hong Kong Polytechnic University, Northeastern University, and Beijing Institute of Technology share third place with 9 studies. Five institutions rank at the end with 6 publications. 


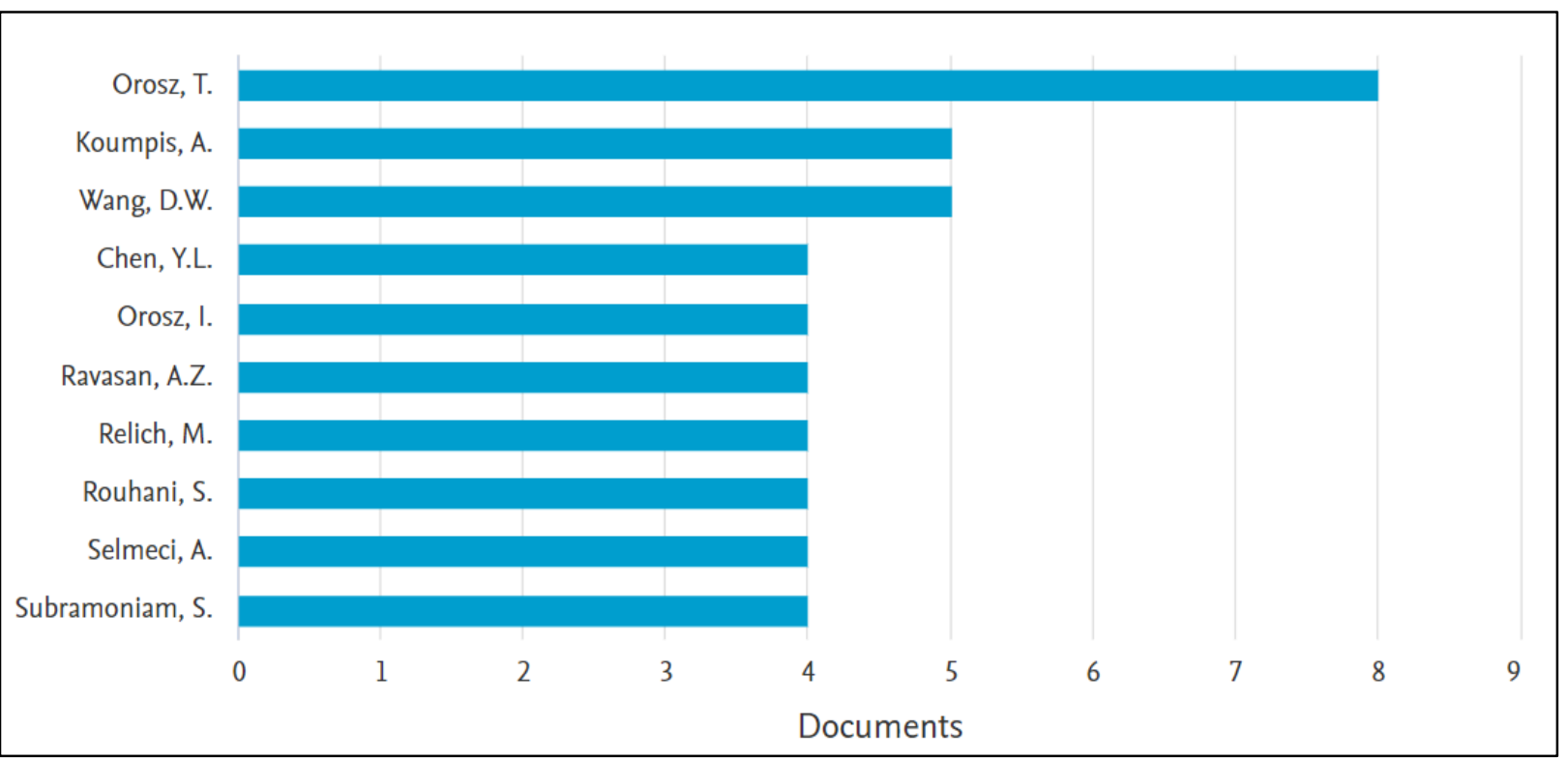

Figure 2. Most published authors.

Table 2. Most publishing institutions on ERP-Al topics

\begin{tabular}{cll}
\hline No & \multicolumn{1}{c}{ Institutions name } & Document \\
1 & Tsinghua University & 12 \\
2 & Obuda University & 9 \\
3 & Hong Kong Polytechnic University & 9 \\
4 & Northeastern University, China & 9 \\
5 & Beijing Institute of Technology & 8 \\
6 & Northwestern Polytechnical University & 8 \\
7 & University of Tehran & 7 \\
8 & Shanghai Jiao Tong University & 7 \\
10 & Amirkabir University of Technology & 6 \\
11 & Harbin Institute of Technology & 6 \\
13 & The University of Hong Kong & 6 \\
& Allameh Tabataba'i University & 6 \\
\end{tabular}

\subsection{Distribution of publications by subject areas}

The distribution of publications by subject areas is presented in Table 3 . It is seen in Table 3 that $65 \%$ of the studies published on ERP-AI subjects cover the field of computer sciences and 50\% cover the field of basic engineering. In addition, these studies fall within the scope of different disciplines such as mathematics, business management and accounting, and decision sciences. Table 3 shows that studies on ERP-AI are also conducted in fields such as energy, physics, astronomy, material science, econometrics, and medicine.

The distribution of publications by years can be used as an indicator of whether the subject continues to attract the attention of researchers. This also applies to the institutional analysis of the authors. It is important to determine which institutions are more pioneers in a specific research, support the studies and try to have a say in the world on that subject. In addition, subjects that fall within the scope of a research topic also give an idea to the researchers working on that subject. For this reason, a photograph of the ERP-AI research area was taken in the study. 
Table 3. Distribution of publications by subject area

\begin{tabular}{lcc}
\hline \multicolumn{1}{c}{ Subject area } & Document & $\%$ \\
Computer science & 549 & 65.59 \\
Engineering & 419 & 50.06 \\
Mathematics & 147 & 17.56 \\
Business, management and accounting & 124 & 14.81 \\
Decision sciences & 120 & 14.34 \\
Social sciences & 35 & 4.18 \\
Multidisciplinary & 33 & 3.94 \\
Energy & 31 & 3.70 \\
Physics and astronomy & 29 & 3.46 \\
Materials science & 22 & 2.63 \\
Economics, econometrics and finance & 21 & 2.51 \\
Medicine & 21 & 2.51 \\
Chemical engineering & 19 & 2.27 \\
Environmental science & 11 & 1.31 \\
\hline
\end{tabular}

\subsection{Bibliometric analysis results}

Results obtained from bibliometric analysis including common author analysis, common citation analysis, and common keyword analysis methods of 296 studies obtained by filtering those in article type from 837 publication studies on ERP-AI subjects as a result of the research are presented in tables, figures, and visual maps.

\subsubsection{Co-author analysis (author, countries)}

It was determined in the co-author analysis of the articles that there was a total of 820 authors in 296 articles and these authors were listed in the VOSviewer software according to the number of citations and the screenshot in Figure 3 was obtained. Baker A. D. received the most references with 233 references among the authors. Zhang Y. ranks second with 212 references whereas Gunasekaran A. is the author who received the third most references with 162 references. The average number of citations of the authors in the first 15 was calculated as 95 according to the number of citations. Ravasan A. Z. has the most publications on ERP-AI with 4 articles.

It is seen that there are 57 authors who cooperate between them when the co-authors of articles with at least two authors are analyzed. The density map of these co-author groups is depicted in Figure 4. Link attribute refers to the number of links an item makes to other items. Total link strength refers to the sum of common links of an item with other items. The authors with the most linking force are Subranomiam S. $(n=6)$, Chen Y., Krishnankutty K. V., and Tounsi M. $(n=5)$, respectively, according to Figure 3 and Figure 4.

The number of countries hosting the article studies was calculated as 57 in the co-author-country analysis. Figure 5 shows the relationship network of 30 countries and those countries identified when countries with at least three studies were analyzed. Countries are clustered in six different colors, depending on their cooperation. All items in the same group are shown in the same color on visual collaboration maps.

The countries with the highest linking force according to the number of linkings are China $(n=22)$, United States $(n=20)$, and United Kingdom $(\mathrm{n}=10)$ in Figure 5. In addition, Hong Kong and India have 7 linkings. Turkey, France, Iran, and Finland rank in the top ten with 5 linkings each.

\subsubsection{Co-citation analysis (author, source)}

23 authors who received at least 20 citations within the scope of common citation-writer analysis were identified. The citation numbers and linking force of 23 authors are presented in Figure 6. 


\begin{tabular}{|l|r|r|r|}
\hline \multicolumn{1}{|c|}{ Author } & Documents & Citations & \multicolumn{2}{c|}{$\begin{array}{c}\text { Total link } \\
\text { strength }\end{array}$} \\
\hline baker a.d. & 2 & 233 & 0 \\
\hline zhang y. & 3 & 212 & 1 \\
\hline gunasekaran a. & 2 & 162 & 0 \\
\hline moradi m.h. & 2 & 151 & 0 \\
\hline ravasan a.z. & 4 & 87 & 3 \\
\hline chang I.-c. & 2 & 68 & 2 \\
\hline yen d.c. & 2 & 68 & 2 \\
\hline chan w.l. & 2 & 64 & 4 \\
\hline sheng s. & 2 & 64 & 4 \\
\hline xianzhong d. & 2 & 64 & 4 \\
\hline wang l. & 2 & 62 & 1 \\
\hline shen w. & 2 & 59 & 1 \\
\hline ip w.h. & 2 & 54 & 1 \\
\hline mitkas p.a. & 2 & 40 & 2 \\
\hline symeonidis a.l. & 2 & 40 & 2 \\
\hline
\end{tabular}

Figure 3. Co-author-author analysis, most cited authors (VOSviewer screenshot).

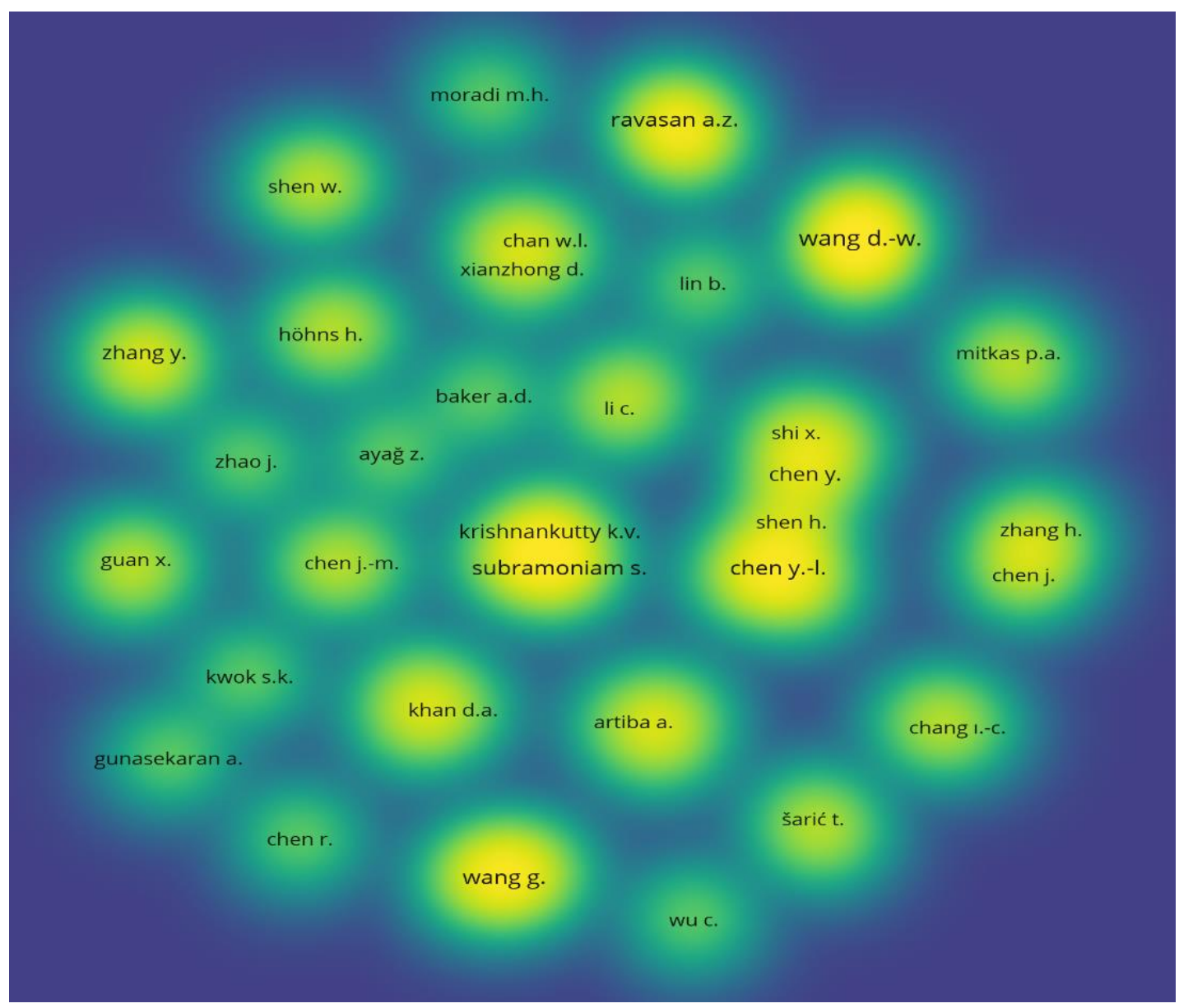

Figure 4. Co-authors density map. 


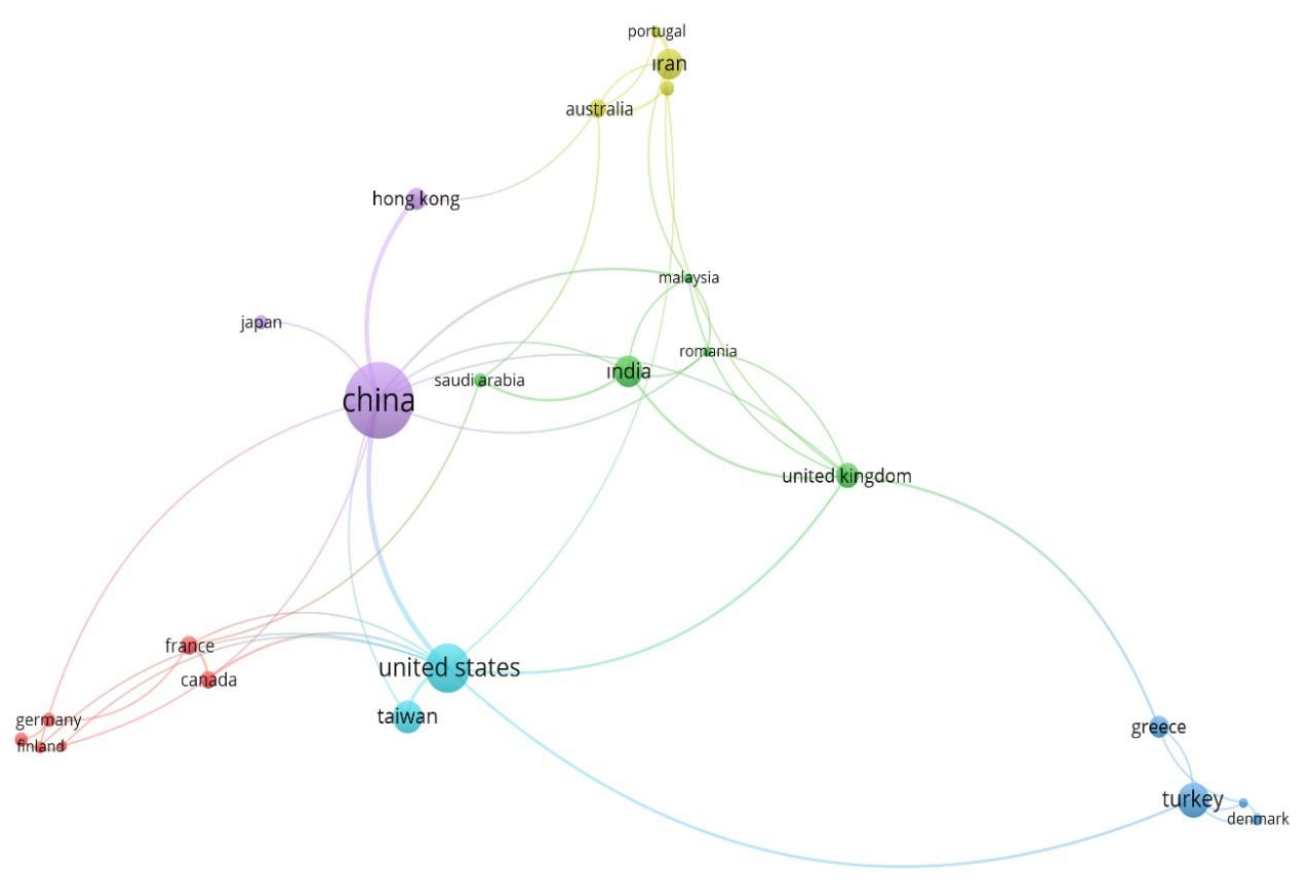

Figure 5. Cooperation map between co-authors' countries.

The most cited co-author was Adeli H. with 43 citations when the numerical results were examined from Figure 6. Saaty T. L. follows Adeli H. with 40 citations. Li Y. and Gunasekaran A. are the other authors in the ranking with 37 and 32 references, respectively. Saaty T. L., which ranks second in the number of citations, ranks first in the linking force $(\mathrm{n}=271)$. Adeli $\mathrm{H}$., on the other hand, ranked first in terms of the number of citations, but could not rank among the top 10 in terms of linking force. This shows that the author does not have much cooperation with other authors even though the author receives a lot of references. A collaboration network between authors in the common citation-writer analysis is shown in Figure 7. Accordingly, four separate clusters were formed and the largest of these clusters was the red cluster with nine authors. There are seven authors in the green cluster, four in the blue cluster, and three in the yellow cluster. Saaty, T. L., Kahramani C, and Xu, L, who have high linking force, are shown to be more emphasized than other authors, and the high number of linkings between authors is understood from Figure 7.

Figure 8 shows the journals found when the most cited sources are analyzed. It is seen that the "European Journal of Operational Research" is the most-cited journal in the studies on ERP-AI subjects when Figure 8 is examined. The total number of citations of the journal was calculated as 194. This journal is followed by the "Expert Systems with Applications" journal with 189 citations. Figure 8 shows that as the number of citations of journals decreases, the linking force generally decreases.

The visual map showing the collaboration between journals is shown in Figure 9. It is understood that the sources are clustered in four groups shown in different colors from the journal network map in Figure 9. It is seen that the journal with the most linkings is "Expert Systems with Applications". This journal is followed by "European Journal of Operational Research", "International Journal of Production Economics", "Decision Support Systems" and "International Journal of Production Research" journals in terms of cooperation.

\subsubsection{Co-occurrences analysis (keyword)}

A total of 1,026 common keywords were reached when the data were examined in the first place for common keyword analysis. Later, typos in the words and similar words expressing the same meaning were edited. For example, because "genetic algorithm" and "genetic algorithms" express the same concept, fewer repetitive "genetic algorithms" expressions are excluded. The most repetitive words obtained in the common word analysis after the corrections are visualized in the map in Figure 10. The most commonly used common keywords in the ERP-AI studies were "ERP" ( $n=37)$, "genetic algorithm" ( $\mathrm{n}=27$ ), "enterprise resource planning" $(\mathrm{n}=25)$, "fuzzy logic" $(\mathrm{n}=22)$, and "machine learning" $(\mathrm{n}=15)$, respectively, according to Figure 10. "Artificial intelligence" keyword has been repeated in only 11 studies since it is a more general title. "Supply chain 


\begin{tabular}{l|r|r|}
\hline \multicolumn{1}{c|}{ Author } & Citations $v$ & \multicolumn{2}{|c|}{$\begin{array}{l}\text { Total link } \\
\text { strength }\end{array}$} \\
\hline adeli, h. & 43 & 84 \\
\hline saaty, t.l. & 40 & 271 \\
\hline li, y. & 37 & 151 \\
\hline gunasekaran, a. & 32 & 137 \\
\hline van der aalst, w.m.p. & 32 & 4 \\
\hline zadeh, l.a. & 31 & 175 \\
\hline kahraman, c. & 30 & 210 \\
\hline sarkis, j. & 29 & 170 \\
\hline wang, l. & 29 & 134 \\
\hline wang, d. & 29 & 48 \\
\hline xu, I. & 28 & 219 \\
\hline al-mashari, m. & 25 & 132 \\
\hline li, h. & 25 & 122 \\
\hline ayag, z. & 24 & 239 \\
\hline davenport, t.h. & 24 & 42 \\
\hline
\end{tabular}

Figure 6. Co-citiation author analysis, most cited authors (VOSviewer Screenshot).

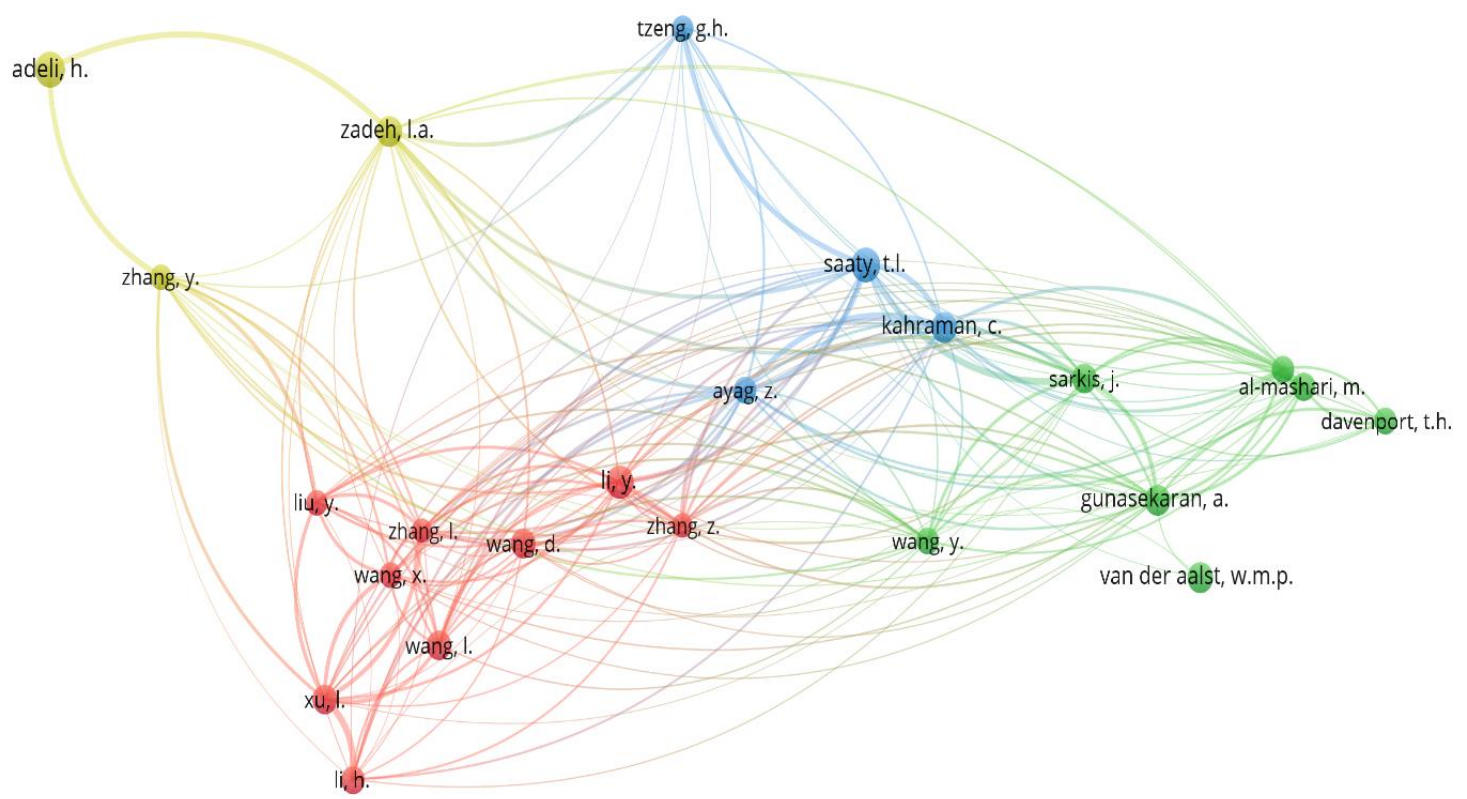

Figure 7. Co-citation-author analysis - citation network between authors.

management", "optimization”, and "decision support systems" were other common keywords repeated 8 times.

\section{Conclusion and discussion}

Descriptive and bibliometric analysis of ERP-AI studies were performed by examining the studies published in the journals scanned in the Scopus database in this study. It is seen that ERP-AI studies have started to be carried out since 1995 and the number of studies has generally increased to date when the descriptive analysis results of the research are examined. The decrease in the number of studies on ERP-AI can be thought to be due to the fact that the customers in the ERP market do not demand the need for development within the scope of AI from their ERP suppliers or do not have sufficient motivation in this regard. It can be said that the increase in the number of publications after 2014, with the emergence of the Industry 4.0 trend as 


\begin{tabular}{|c|c|c|}
\hline Source & Citations $\checkmark$ & $\begin{array}{l}\text { Total link } \\
\text { strength }\end{array}$ \\
\hline european journal of operational research & 194 & 2251 \\
\hline expert systems with applications & 189 & 2433 \\
\hline International journal of production research & 140 & 1444 \\
\hline International journal of production economics & 121 & 1558 \\
\hline decision support systems & 82 & 1506 \\
\hline management science & 61 & 570 \\
\hline computers in Industry & 58 & 682 \\
\hline Industrial management $\&$ data systems & 47 & 882 \\
\hline harvard business review & 43 & 409 \\
\hline journal of operations management & 42 & 487 \\
\hline omega & 41 & 439 \\
\hline fuzzy sets and systems & 41 & 437 \\
\hline computers $\&$ industrial engineering & 39 & 564 \\
\hline communications of the acm & 37 & 209 \\
\hline Information \& management & 36 & 595 \\
\hline business process management journal & 36 & 510 \\
\hline Int. j. prod. econ. & 36 & 43 \\
\hline Information sciences & 35 & 536 \\
\hline
\end{tabular}

Figure 8. Co-citation - source analysis, most cited journals (VOSviewer Screenshot).

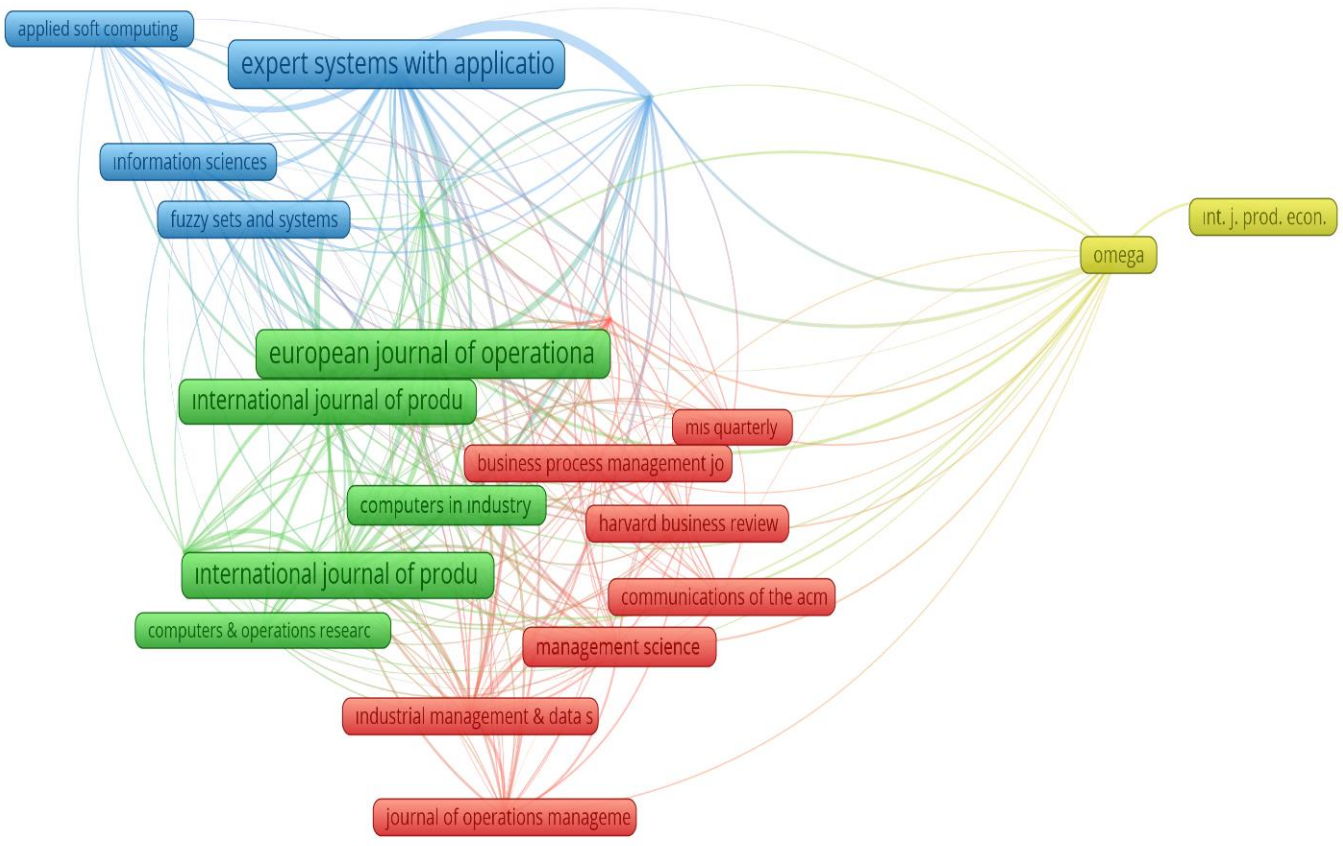

Figure 9. Co-citation - source analysis, citation network between journals.

of 2012, accelerated the prominence of AI in production and business processes. It is understood that more than half of the studies conducted on this subject are in conference paper type and one-third are in article type. Almost all of the studies were conducted in English and most studies were conducted in 2018. Tsinghua University and Obuda University have the most studies. The subject area of the studies is mostly Computer Science and Engineering. On the other hand, it has been observed that there are studies conducted in many fields as multidisciplinary.

The authors who received the most references were Baker A. D., Zhang Y., and Gunasekaran A. when the bibliometric analysis results were examined. Ravasan A. Z. is the author with the most articles. The authors with the most linking force in co-author analysis are Subranomiam S., Chen Y., Krishnankutty K. V., and Tounsi M., respectively. The countries with the highest linking force were China, United States, and the United Kingdom. The most cited authors in the joint citation analysis 


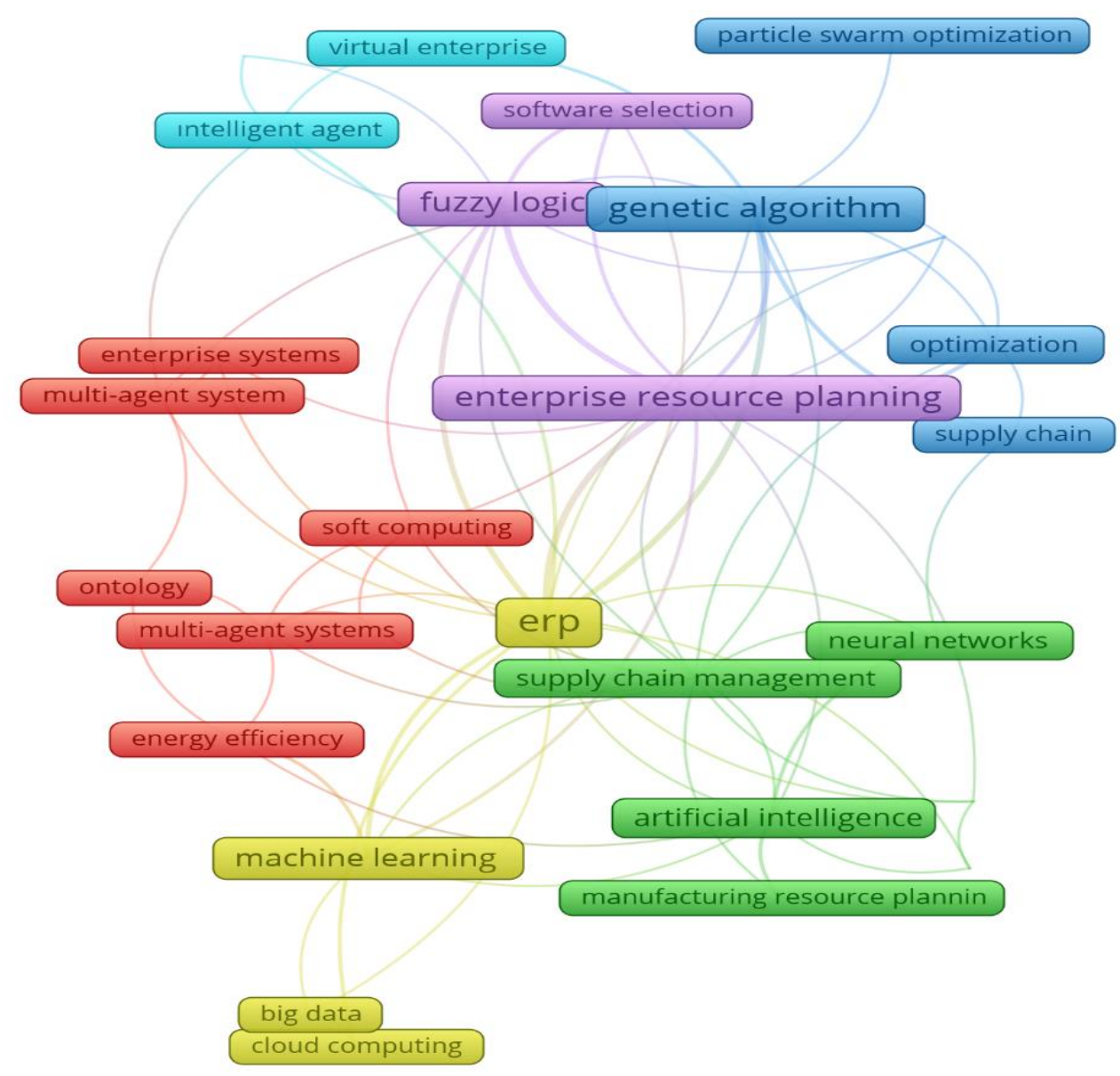

Figure 10. Co-occurrences keyword analysis results.

were Adeli H., Saaty T. L., Li Y., and Gunasekaran A. It is noteworthy that there are different names among the authors who received the most references and among the common references. However, it is noteworthy that there is a writer named Gunasekaran A. in both analyzes. It is understood from the analysis results that the studies of the related author are at the forefront in both author analysis and common citation analysis. The most commonly cited journal sources are the "European Journal of Operational Research" and "Expert Systems with Applications" journals. It is seen that there is a positive relationship between the number of citations and linking force as the number of citations of journals increases. The most frequently used common keywords are "ERP", "enterprise resource planning", "genetic algorithm", "fuzzy logic", and "machine learning". This is an indication that genetic algorithms, fuzzy logic, and machine learning methods are the most preferred AI techniques in ERP studies.

AI creates opportunities that include improving the efficiency of business processes and resources in business management. Especially when integrated with ERP in a supply chain, it enables effective decisions to be made by integrating business processes with machinery and sensors in planning, production and shipment stages. In a smart business where processes are more intelligent, analyzing real costs such as production and logistics, using resources efficiently, ensuring customer satisfaction in business processes directly affects profitability and competitiveness. Therefore, this study focuses on what is done with AI techniques in ERP in order for a company to maintain its commercial existence, profitability and competitiveness. In this study, it is aimed to get ideas about which trends companies should pay attention to in the AI perspective on ERP in the near future. Thus, it has been shown that many opportunities can be obtained by using AI techniques in ERP systems in order to reduce logistics costs, which are the costliest after raw material costs in production, to improve logistics business processes, to reduce shipping times and to better meet customer expectations.

Descriptive and bibliometric analyses of ERP-AI studies are performed and a broad evaluation of AI studies on ERP is presented to researchers and experts in this study. This study aims to guide the studies of the researchers by seeing the most 
popular research topics by seeing the authors, institutions, and countries who do the most research on this subject. Big data, the Internet of Things, sensors, and robotics topics have attracted more attention and accelerated ERP integration and AI studies, especially with the Industry 4.0 trend. This study completes an important gap in ERP, especially since a systematic literature review or bibliometric analysis study on ERP-AI has not been conducted before. A roadmap was presented to researchers to prevent repetition in future studies by providing a new perspective to the literature in the field of ERP-AI, which has a multidisciplinary field of study in computer sciences, engineering, business management, and other social sciences in the research. In this study, the Scopus database was used in the data collection process and the data were analyzed and visualized with the VOSviewer software. Future studies can be based on the WoS database. Analyzes and visualizations can be made using software such as SCIMAP, CiteSpace R, Python. In addition, in this study, the subject of ERP has been examined in a broad perspective in terms of AI. In future studies, a specific business process (eg sales management, shipping process, accounting) can be handled with a specific AI technique. Descriptive, bibliometric, and meta-analysis studies can be conducted together on these subjects.

\section{References}

Al-Mashari, M., Al-Mudimigh, A., Zairi, M., 2003. Enterprise resource planning: A taxonomy of critical factors. European Journal of Operational Research 146, 352-364.

Ardito, L., Scuotto, V., Del Giudice, M., Petruzzelli, A. M., 2019. A bibliometric analysis of research on big data analytics for business and management. Management Decision 57, 1993-2009.

Azevedo, P. S., Romão, M., Rebelo, E., 2014. Success factors for using ERP (enterprise resource planning) systems to improve competitiveness in the hospitality industry. Tourism \& Management Studies 10, 165-168.

Bahssas, D. M., AlBar, A. M., Hoque, M. R., 2015. Enterprise resource planning (ERP) systems: Design, trends and deployment. The International Technology Management Review 5, 72-81.

Cadersaib, B. Z., Ahku, Y., Sahib-Kaudeer, N. G., Khan, M. H. M., Gobin, B., 2020. A review of skills relevant to enterprise resource planning implementation projects. Proceedings of the 2020 International Conference on Informatics, Multimedia, Cyber and Information System (ICIMCIS), Jakarta, Indonesia.

Çiftçi, Ö, 2005. An artificial intelligence application at the alternative supplier medium for the selection of supplier. Electronic Letters on Science and Engineering 1, 1-6.

Cong, W., Shi, L., 2019. Heterogeneity of industrial development and evolution of cleaner production: Bibliometric analysis based on JCLP. Journal of Cleaner Production 212, 822-836.

Gibson, N., Holland, C., Light, B., 1999. Enterprise resource planning: A business approach to systems development. Proceedings of the 32nd Annual Hawaii International Conference on Systems Sciences, Maui, HI.

Gür, Y. E., Ayden, C., Yücel, A., 2019. Yapay zekâ alanindaki gelişmelerin insan kaynakları yönetimine etkisi. Firat Üniversitesi Uluslararası İktisadi ve İdari Bilimler Dergisi 3, 137-158.

Inacio, H., Marques, R. P., 2018. Analysis of the research on internal control in enterprise resource planning systems. Proceedings of the 2018 13th Iberian Conference on Information Systems and Technologies (CISTI), Caceres, Spain.

Ivanov, D., Tang, C. S., Dolgui, A., Battini, D., Das, A., 2020. Researchers' perspectives on Industry 4.0: Multi-disciplinary analysis and opportunities for operations management. International Journal of Production Research 59, 2055-2078.

Janssens, G., van Moorst, L., Kusters, R., Martin, H., 2020. An expert-based taxonomy of ERP implementation activities. Journal of Computer Information Systems 60, 175-183.

Korkmaz, G., 2020. Yapay zekâ yöntemleriyle sınıflandırma ve finans sektöründe bir uygulama. Akademik Yaklaşımlar Dergisi, 11(2), 91-109.

Lizano-Mora, H., Palos-Sanchez, P. R., Aguayo-Camacho, M., 2021. The evolution of business process management: A bibliometric analysis. IEEE Access 9, 51088-51105.

Mladenova, T., 2020. Open-source ERP systems: An overview. Proceedings of the 2020 International Conference Automatics and Informatics (ICAI), Varna, Bulgaria.

Mourao, P. R., Martinho, V. D., 2020. Forest entrepreneurship: A bibliometric analysis and a discussion about the co-authorship networks of an emerging scientific field. Journal of Cleaner Production 256, 120413.

Nabiyev, V. V., 2012. Yapay Zeka: Insan-Bilgisayar Etkileşimi. Seçkin Yayıncılık, Ankara, Turkey.

Öztürk, K., Şahin, M. E., 2018. Yapay sinir ağları ve yapay zekâ'ya genel bir bakış. Takvim-i Vekayi 6, 25-36.

Pirim, A. G. H., 2006. Yapay zeka. Journal of Yaşar University 1, 81-93. 
Prashar, A., 2020. A bibliometric and content analysis of sustainable development in small and medium-sized enterprises. Journal of Cleaner Production 245, 118665.

Pulat, M., Kocakoc, İ. D., 2019. Gezgin satıcı probleminin genetik algoritmalar kullanarak çözümünde çaprazlama operatörlerinin örnek olaylar bazlı incelenmesi. İzmir İktisat Dergisi 34, 225-243.

Schlichter, B. R., Kraemmergaard, P., 2010. A comprehensive literature review of the ERP research field over a decade. Journal of Enterprise Information Management 23, 486-520.

Tektaş, M., Akbaş, A., \& Topuz, V., 2002. Yapay zekâ tekniklerinin trafik kontrolünde kullanilmasi üzerine bir inceleme. Uluslararası Trafik ve Yol Güvenliği Kongresi, Gazi Üniversitesi, Ankara.

Türk, E., Kiani, F., 2019. Yapay sinir ağları ile talep tahmini yapma: Beyaz eşya üretim planlaması örneği. İstanbul Sabahattin Zaim Üniversitesi Fen Bilimleri Enstitüsü Dergisi 1, 30-37.

Ünver, M., Altunok, C., 2020. Medikal endüstride yapay zeka ve uzman sistemlerin sürekli iyileştirmeye etkisi. Proceedings of the 8th International Symposium on Innovative Technologies in Engineering and Science (ISITES2020), Bursa, Turkey. 